\title{
CONTRATO DE UNDERWRITING
}

\section{Vinicius Figueiredo Chaves* Marcelo Pereira dos Santos**}

\section{RESUMO}

Este trabalho tem por objeto os aspectos jurídicos do underwriting, termo genérico utilizado para a designação da relação contratual entre emissor e intermediário financeiro das operações de emissão e colocação de títulos/valores mobiliários. Valendo-se do método de pesquisa qualitativo, de caráter exploratório, bem como do raciocínio dedutivo e da metodologia fundada na revisão bibliográfica documental, pretende-se descrever as variantes do contrato de underwriting e identificar as múltiplas dimensões de risco que recaem sobre as partes contratantes, a fim de delimitar seu conceito na ordem jurídica brasileira. Preliminarmente, conclui-se que o underwriting não é puramente uma cláusula de pré-financiamento.

Palavras-Chave: Oferta Pública; Valores Mobiliários; Contrato; Underwriting; Risco.

\section{UNDERWRITING AGREEMENT}

\section{AbSTRACT}

This work has for object the legal aspects of underwrinting, generic term usually used to describe the contractual relationship between issuer and financial intermediary of an operation of issue and placement of bonds/securities. Using the method of qualitative research, exploratory, and deductive reasoning and the methodology based on literature review, it is intended to describe the variants of the underwriting agreement and identify the multiple dimensions of risk that fall on the contracting parties, in order to delimit your concept in the brazilian legal system. Preliminarily, it appears that the underwriting is not purely a prefinancing.

KEYWORDS: Public Offering; Securities; Contract; Underwriting; Risk.

\section{INTRODUÇÃO}

Em meio a diferentes alternativas para o provimento de capital financeiro, encontrase à disposição de certos agentes econômicos o procedimento de oferta pública de valores mobiliários realizada no âmbito dos mercados de capitais. Esta complexa operação é

\footnotetext{
* Doutor em Direito pela Universidade do Estado do Rio de Janeiro, na linha de pesquisa Empresa e Atividades Econômicas. Professor permanente do PPGD da UNESA. Professor Adjunto da UFRJ e da UFF viniciuschaves@gmail.com

** Doutorando e Mestre em Direito Público e Evolução Social pela Universidade Estácio de Sá - RJ. Coordenador do Curso de Graduação em Direito e Professor dos Cursos de Pós-Graduação Lato Sensu da Universidade Estácio de Sá - RJ - marcelo.pereira.adm.ufrrj@gmail.com
} 
compreendida por etapas como a emissão, a subscrição, a colocação e a distribuição dos títulos - normalmente títulos de participação ou de dívida emitidos pelas sociedades por ações - junto ao mercado ${ }^{1}$.

Tal modalidade de captação de recursos financeiros, que se opera por intermédio de oferta de valores mobiliários aos investidores, tem como regra a intermediação de uma instituição financeira especialmente autorizada. Decorre daí a necessidade de celebração de um contrato para disciplinar as relações jurídicas que se estabelecem entre a sociedade emissora dos títulos - normalmente uma sociedade por ações - e a instituição financeira intermediária.

Este negócio jurídico celebrado para disciplinar o complexo processo que envolve as etapas da oferta pública de valores mobiliários no mercado de capitais é conhecido genericamente como contrato de underwriting. Seu objeto imediato tem sido apontado na literatura como sendo o pré-financiamento de uma operação de emissão de títulos/valores mobiliários, onde a instituição financeira intermediária, em tese, atuaria no sentido da subscrição dos títulos para posterior revenda. Obraria, desta forma, no direcionamento direto dos recursos financeiros ao emissor dos títulos/valores mobiliários, com a assunção do chamado risco pela colocação dos títulos/valores mobiliários.

O assunto em questão desafia uma série de análises e reflexões. Uma delas, por sua relevância, põe-se como situação-problema que fundamenta a presente investigação: É apropriado definir genericamente o underwriting como um contrato de pré-financiamento, pelo qual a instituição financeira será sempre responsável por atuar no sentido do direcionamento de recursos ao emissor dos títulos/valores mobiliários, subscrevendo-os para posterior revenda ao mercado?

Partindo-se da situação-problema delineada acima, o objetivo geral do artigo é analisar esta modalidade contratual e as relações jurídicas que a compreendem, com foco na perspectiva do ordenamento jurídico brasileiro, especialmente com a finalidade de demonstrar que o tipo contratual em questão permite o estabelecimento de diferentes espécies de ajustes entre as partes contratantes. Neste sentido, a construção de resposta adequada à indagação

\footnotetext{
${ }^{1}$ Para os fins deste trabalho, considerar-se-á: i) emissão: o conjunto de atos destinados à criação de valores mobiliários; e ii) distribuição/colocação: a respectiva introdução originária destes valores mobiliários perante o mercado, após proposta contratual dirigida ao público. Neste sentido, a colocação dependerá da subscrição, ou seja, a aceitação por parte de investidores das condições fixadas pelo ofertante. Realizada a subscrição, torna-se o investidor adquirente titular dos valores mobiliários objeto da oferta.
} 
formulada dependerá da compreensão sobre os contornos específicos de tais modalidades, cujos acordos acabam conformar situações jurídicas distintas no que diz respeito à relação emissor/intermediário financeiro.

A pesquisa se justifica em função do destacado papel que o negócio jurídico em questão ocupa nas operações de emissão e colocação/distribuição de valores mobiliários no mercado de capitais, que se operam com a finalidade principal de canalização de recursos para as atividades desempenhadas pelos agentes econômicos. Trata-se de um tema pouco explorado pela doutrina e marcado por elevada complexidade, na medida em que, a um só tempo, a sua discussão perpassa tanto a dinâmica da disciplina jurídica dos contratos empresariais em geral quanto as dimensões das atribuições conferidas aos órgãos reguladores dos mercados de capitais, particularmente a chamada função normativa. Embora praticamente ausentes nos debates cotidianamente realizados no Grupo de Trabalho de DIREITO EMPRESARIAL do CONPEDI, o tema e os subtemas aqui tratados se inserem nos eixos de preocupação epistêmica constantes na ementa deste GT, corroborando a justificativa para o estudo.

A fim de analisar a questão orientadora da investigação, abordam-se inicialmente as origens etimológica e histórica underwriting, assim como aspectos da complexa operação de emissão e distribuição/colocação de valores mobiliários e os principais contornos jurídicos do contrato que a instrumentaliza ${ }^{2}$. Posteriormente, passa-se ao exame das modalidades de underwriting e do seu conceito, cuja compreensão constitui ponto chave para a solução do problema de pesquisa. Na sequência, examina-se o underwriting no contexto do ordenamento jurídico brasileiro, sendo destacadas algumas comparações pontuais com a realidade portuguesa $^{3}$ e as principais questões jurídicas em torno das instruções normativas da Comissão de Valores Mobiliários que disciplinam a matéria.

Realizou-se uma pesquisa qualitativa, com perfil exploratório e baseada nas técnicas de revisão bibliográfica e documental, por meio de análise de documentos legais, livros e artigos científicos assinados por autores nacionais e internacionais. Adotou-se uma linha de raciocínio dedutivo.

\footnotetext{
${ }^{2}$ Há uma série de aspectos econômicos interessantes e merecedores de análise em torno do underwriting, mas a sua enunciação e abordagem, num trabalho limitado a 20 laudas, poderiam implicar em superficialidade. Para não se comprometer o aprofundamento da abordagem aqui empreendida, optou-se por um esforço no sentido de um maior recorte e delimitação temática aos aspectos jurídicos.

${ }^{3}$ A comparação não constitui um objetivo específico do presente trabalho, mas apenas uma forma de enriquecimento das informações trazidas ao leitor. Deste modo, não se utilizarão métodos específicos de análise comparativa por semelhanças ou por diferenças.
} 


\section{UNDERWRITING: ORIGENS ETIMOLÓGICA E HISTÓRICA}

A palavra underwriting, de origem anglo-saxã, deriva do verbo inglês to underwrite, que significa subscrever, rubricar, assinar embaixo (TORRES, 2010, p. 115).

A origem mais remota do underwriting é apontada como sendo a quadra final do século XVII, na Inglaterra, no bojo do contrato de seguro marítimo, no qual os underwriters atuavam na subscrição deste contrato e, assim, assumiam os riscos decorrentes das navegações em troca de uma determinada contraprestação, normalmente financeira.

Posteriormente, já nos séculos XVIII e XIX, com o surgimento e desenvolvimento da indústria, passa a ser mais premente a necessidade de financiamento para os agentes econômicos. É neste contexto que surge uma atividade específica levada a cabo por intermediários financeiros, que consistia na subscrição de títulos emitidos pelas sociedades anônimas carecedoras de recursos, para em seguida revendê-los no mercado a um melhor preço. A esta atividade do intermediário, de cunho então eminentemente especulativo, deu-se o nome underwriting ${ }^{4}$.

\section{UNDERWRITING: ASPECTOS DA COMPLEXA OPERAÇÃo DE EMISSÃo E} DISTRIBUiÇÃo/COLOCAÇÃo DE VALORES MOBILIÁRIOS E PRINCIPAIS CONTORNOS JURÍDICOS DO CONTRATO QUE A INSTRUMENTALIZA

Contemporaneamente, a referência ao termo underwriting guarda relação com uma situação onde um agente econômico, em colaboração com um intermediário financeiro, oferece títulos/valores mobiliários de sua emissão com a finalidade de captação de recursos para o financiamento de suas atividades. Tais títulos/valores - cuja natureza pode ser de participação ou de dívida - são subscritos por terceiros, agentes superavitários detentores de capital, os quais, por sua vez, atuam na condição de investidores com a finalidade de aquisição de uma participação societária (ex.: compra de uma ou mais ações) ou então simplesmente em busca de rentabilidade para o capital investido (ex.: compra de uma ou mais debêntures).

\footnotetext{
${ }^{4}$ Conforme lembram Nelson Eizirik et al (2011, p. 180), o termo underwriter teria sido tomado de empréstimo da legislação sobre seguros, sendo naquele contexto utilizado para como referência à atividade consistente em "segurar" o emissor de papéis contra eventuais perdas oriundas do insucesso da colocação dos mesmos.
} 
Do ponto de vista jurídico, as etapas que envolvem o complexo processo de uma oferta de títulos/valores mobiliários, como emissão, colocação e distribuição, são ajustadas contratualmente pelas partes intervenientes, quais sejam, o emissor dos títulos/valores mobiliários e o intermediário financeiro ou um conjunto de instituições intermediárias organizadas sob a forma de consórcio. Deste contrato derivam compromissos variáveis assumidos pelas partes e também vantagens recíprocas.

O emissor normalmente será uma sociedade empresária organizada sob a forma de sociedade por ações ${ }^{5}$, em busca de capital financeiro para o exercício das atividades econômicas desenvolvidas. Em linhas gerais, quando da celebração do pacto, a companhia já terá deliberado sobre as opções de financiamento de curto, médio e longo prazo à disposição, tendo a escolha recaído na emissão de títulos de participação ou de dívida, considerados os seus impactos econômicos e também jurídicos. O passo seguinte será a escolha do intermediário, a qual deve levar em consideração a expertise da instituição financeira, na medida em que "a força e a tradição do underwriter no mercado também influenciam o sucesso da operação, pois se uma instituição renomada aceitou a missão da colocação, está dando seu aval ao papel” (CASAGRANDE NETO; SOUSA \& ROSSI, 2000, p. 60) ${ }^{6}$. Além disto, deve-se também ter em conta que "o underwriting não pode ser exercido por qualquer pessoa, mas tão somente por aquelas instituições financeiras legalmente autorizadas para o exercício de tal atividade", ou seja, habilitadas ao desempenho de intermediação financeira no mercado de valores mobiliários (EIZIRIK, 1987, p. 20) ${ }^{7}$.

A participação de um intermediário financeiro nas ofertas públicas de valores mobiliários, destaca Catarina Rodrigues (2012, p. 35), visa salvaguardar princípios como a proteção do mercado e a confiança dos investidores. Outro princípio igualmente relevante é o disclosure, que impõe a plena divulgação de informações sobre a emissora e os detalhes importantes da operação (WALD; EIZIRIK, 1984, p. 54). Aliás, a necessidade de salvaguarda destes princípios traz para o underwriter a responsabilidade pela veracidade das informações

\footnotetext{
${ }^{5}$ No Brasil, a Instrução CVM 400/03, que dispõe sobre as ofertas púbicas de valores mobiliários, nos mercados primário e secundário em geral, permite a realização de ofertas públicas de valores mobiliários emitidos por "micro e pequena empresa", organizadas sob formas societárias distintas das sociedades por ações.

6 "Nos lançamentos públicos de ações os investidores depositam grande confiança nos underwriters que participam da operação, especialmente se estes forem instituições sólidas e de renome” (BOCATER, 1998, p. 2).

${ }^{7}$ A Instrução CVM 400/03, em seu Art. $3^{\circ}, \S 2^{\circ}$ impõe que as ofertas sejam realizadas com intermediação das denominadas "instituições intermediárias", isto é, instituições financeiras integrantes do sistema de distribuição de valores mobiliários. A regulação no âmbito da Comissão de Valores Mobiliários será tratada em tópico específico sobre o underwriting no ordenamento jurídico brasileiro.
} 
veiculadas $^{8}$, na medida em que a informação consiste no principal instrumento de defesa do público investidor, devendo ser suficientemente precisa e completa em seu conteúdo e extensão (MELO; JUNQUEIRA \& BERCITO, 2014, p. 115).

Encontra-se, assim, o underwriter diante dos deveres de cautela relacionados à atividade específica e profissional que desempenha, devendo agir com elevados padrões de diligência. Incumbe-lhe, neste sentido, conferir suficientemente as informações prestadas pelo emissor, examinando-as quanto à veracidade e fidedignidade, assumindo uma postura independente frente à companhia (EIZIRIK, 1987, p. 27) ${ }^{9}$.

\section{MODALIDADES DE UNDERWRITING}

A doutrina aponta diferentes modalidades de contrato de underwriting. Entretanto, parece mais ajustado dizer que se trata de um mesmo tipo contratual em que podem ser distintas as formas de garantia eventualmente assumidas pela instituição financeira, o underwriter, sendo possível ao mesmo ajustar compromissos variados em relação à garantia da subscrição, à colocação e ao risco pela colocação dos títulos/valores mobiliários perante o mercado $^{10}$.

Muito embora seja possível encontrar na doutrina outras formas de garantia ${ }^{11}$, as normalmente veiculadas são: i) regime de garantia firme; ii) regime de garantia residual (stand by); e iii) regime de melhores esforços (best efforts) ${ }^{12}$.

\footnotetext{
${ }^{8}$ Há um caso concreto que se tornou paradigmático em âmbito nacional, envolvendo a apuração de irregularidades em operação de emissão de valores mobiliários. O julgamento culminou na responsabilização de instituições financeiras na condição de underwriters, decorrente da sonegação de informações relevantes e consequente indução de terceiros a erro. No voto proferido pela então diretora da Comissão de Valores Mobiliários, Maria Isabel do Prado Bocater, relatora no Inquérito Administrativo CVM 17/92, consolidado e publicado na Revista de Direito Bancário e do Mercado de Capitais, foi destacado o dever de diligência dos underwriters e a sua extensão a todas as fases do processo de distribuição, padrão de comportamento que impõe elevada cautela inclusive no que diz respeito à conferência da veracidade das informações prestadas pelo emissor, não podendo simplesmente se fiar a elas. Neste sentido, ver: BOCATER (1998, p 1-8).

${ }^{9}$ Rui Pinto Duarte (2000, p. 364), ao tratar dos deveres de informação do intermediário, destaca que o Art. 312 do Código de Valores Mobiliários Português estabelece uma regra segundo a qual a extensão e a profundidade da informação deverão ser tanto maiores quanto menor for o grau de conhecimentos e de experiência do cliente. Conclui que a regra em questão visa proteger os investidores com menos experiência no mercado, os chamados investidores não institucionais.

${ }^{10}$ A precificação do risco assumido contratualmente irá refletir na remuneração devida pela sociedade emissora à instituição financeira. Quanto maior o grau de garantia oferecido pelo intermediário, maior será a contraprestação financeira exigida.

${ }^{11}$ Ari Cordeiro Filho (1981, p. 89), por exemplo, destaca o regime de garantia "tudo ou nada" (all or nothing), em que "a garantia da emissão só se tornará efetiva se, dentro de um período determinado, forem encontrados subscritores para todos os valores mobiliários".

${ }^{12}$ Neste sentido, ver Nelson Eizirik (1987, p. 20).
} 
$\mathrm{Na}$ garantia firme o underwriter se compromete a adquirir integralmente os títulos/valores mobiliários emitidos pela sociedade por ações para em seguida revendê-los diretamente ao mercado, assumindo assim o chamado risco pela colocação dos mesmos. Esta modalidade é a mais benéfica do ponto de vista da sociedade emissora e, por outro lado, concentra maior risco para o underwriter ${ }^{13}$.

No regime residual a instituição financeira intermediadora inicialmente se compromete a atuar diretamente na colocação dos títulos/valores mobiliários até um prazo determinado. Até esse momento ajustado, a obrigação assumida pela intermediadora é somente empreender os melhores esforços para colocar no mercado do maior número possível de títulos/valores mobiliários emitidos. $\mathrm{O}$ underwriter se compromete a adquirir unicamente os não colocados efetivamente perante o mercado.

Por fim, no regime de melhores esforços a instituição financeira intermediadora se compromete exclusivamente a empreender os melhores esforços para colocar no mercado o maior número possível de títulos/valores mobiliários emitidos, sem assumir qualquer risco pela colocação efetiva da totalidade e nem mesmo pela subscrição, ela própria, dos títulos/valores.

Importante salientar que, em alguns casos, tem-se como conveniente o ajustamento da utilização de uma única modalidade de garantia. Não obstante, há situações nas quais se apresenta como oportuna a combinação das modalidades, por exemplo, numa operação específica em que o intermediário se compromete com garantia firme sobre uma parcela da emissão, ao passo que em outra parcela fica a garantia vinculada ao regime de melhores esforços (CASAGRANDE NETO; SOUSA \& ROSSI, 2000, p. 59).

A modalidade assumida é também relevante no que diz respeito à indicação da natureza da responsabilidade assumida pelo underwriter, ou seja, se este encontra-se diante de uma obrigação de meio ou de resultado. No regime de melhores esforços ${ }^{14}$ a obrigação é tipicamente de meio, ao passo que nas modalidades com garantia (firme ou mesmo residual) a

\footnotetext{
${ }^{13}$ No mesmo sentido, a doutrina de Catarina Rodrigues (2012, p. 35): "Entre as modalidades de colocação de valores mobiliários à disposição do oferente, a tomada firme é aquela que lhe proporciona uma maior segurança no que respeita ao sucesso da oferta, em contrapartida de um maior risco assumido pelo intermediário financeiro, em virtude da aquisição prévia dos valores mobiliários objecto da oferta".

${ }^{14}$ Catarina Rodrigues (2012, p. 45), ao examinar o regime de melhores esforços no contexto português, descreve: "Trata-se de uma obrigação de diligência, na qual o intermediário financeiro se limita a pôr os seus meios materiais e humanos à disposição da entidade oferente. Os valores mobiliários são colocados sem que se assegure o resultado da oferta, ou seja, sem que advenha qualquer responsabilidade, para o intermediário financeiro, quanto ao eventual insucesso da operação, desde que este haja cumprido todos os deveres a que está vinculado" (grifamos).
} 
obrigação será de resultado na medida em que em ambos os casos o emissor terá a certeza de que os títulos/valores mobiliários serão integralmente colocados, seja por intermédio de subscrição direta integral pelo próprio intermediário, seja por sua subscrição após a não colocação da totalidade da emissão perante o mercado (EIZIRIK, 1987, p. 23-24).

\section{UNDERWRITING: CONTRATO DE PRÉ-FINANCIAMENTO?}

Em relação à questão da natureza contratual, pode-se definir o underwriting como um contrato de pré-financiamento, com subscrição de títulos/valores mobiliários pelo intermediário financeiro para posterior revenda?

Segundo Nelson Eizirik (1987, p. 23), o “contrato firmado entre a companhia emissora e o underwriter recebe usualmente a denominação de 'contrato de garantia de subscrição (quando se trata de underwriting firme ou de stand by), ou de "contrato de colocação' (no caso de underwriting de melhor esforço)".

Percebe-se, assim, que somente em alguns contratos de underwriting haverá efetiva garantia de subscrição por parte do underwriter - da totalidade dos títulos (caso do underwritng firme) ou mesmo da parcela não subscrita pelo público (caso do stand by) -, ao passo que em outros não existirá a referida garantia, como na hipótese de contratação da modalidade best efforts (WALD; EIZIRIK, 1984, p. 56) ${ }^{15}$.

$\mathrm{Na}$ hipótese de contratação de garantia firme ${ }^{16}$ o underwriter, ao adquirir integralmente os títulos/valores mobiliários emitidos pela sociedade por ações, efetivamente atuará no pré-financiamento da operação de emissão, direcionando diretamente recursos para o caixa da emissora.

\footnotetext{
${ }^{15}$ No artigo em questão, ao inicialmente tratarem das características do underwriting, Arnoldo Wald e Nelson Eizirik (1984, p. 54) destacam que "o contrato de underwriting tem por objeto a subscrição de valores mobiliários, por parte de instituição financeira autorizada a desempenhar tal atividade, com vistas à revenda de tais títulos ao público". Em seguida, acertadamente reconhecem que somente em determinados contratos de underwriting há efetiva garantia de subscrição por parte do underwriter". Neste sentido, talvez se apresente como mais ajustado enfatizar que, muito embora a tradução literal do termo esteja atrelada à noção de subscrição, o contrato pode ter, ou não, a subscrição como objeto. Na prática, como já naquela ocasião sinalizavam os autores, o intermediário financeiro atua na colocação dos títulos/valores mobiliários junto ao público investidor.

${ }^{16}$ A Instrução CVM 400/03, embora referencie a modalidade de garantia firme (como, por exemplo, em seu Art. 36), não a define. O Art. 339 do Código de Valores Mobiliários de Portugal define adequadamente o regime de tomada/garantia firme, estabelecendo que: "Pelo contrato de tomada firme o intermediário financeiro adquire os valores mobiliários que são objecto da oferta pública de distribuição e obriga-se a colocá-los por sua conta e risco nos termos e nos prazos acordados com o emitente ou com o alienante".
} 
Celebrada garantia residual, duas situações distintas podem ocorrer: i) colocação total (onde a instituição financeira intermediária alcança êxito total na colocação dentro do prazo ajustado e, portanto, não necessitará adquirir o remanescente dos títulos/valores mobiliários não colocados); e ii) colocação parcial (onde a instituição financeira, não alcançando êxito total na colocação dentro do prazo ajustado, necessitará adquirir o remanescente dos títulos/valores mobiliários não colocados). Tecnicamente, como a instituição financeira somente será responsável pela aquisição do remanescente, o risco somente será a ela transferido na eventualidade da não colocação integral. Assim mesmo, não consistirá numa operação de pré-financiamento, mas talvez de pós-financiamento, na medida em que somente atuará no desembolso de recursos para a emissora se e após não colocar no mercado parte dos títulos/valores mobiliários emitidos.

No caso específico da contratação exclusiva do regime de melhores esforços, não há pré-financiamento, ou seja, a sociedade emissora assume o risco integral pelos eventuais títulos/valores mobiliários eventualmente não colocados, não obstante os melhores esforços neste sentido por parte do underwriter, sendo devolvidos os títulos à emissora ao final da operação $^{17}$.

O esclarecimento acima é especialmente relevante para a adequada compreensão das possíveis estruturas jurídicas do instituto. Quanto ao tema específico, oportuno destacar a lição de Ari Cordeiro Filho (1981, p. 88), para quem:

O contrato de underwriting, em si, pode ser entendido não só como aquilo que sua
tradução literal sugere, ou seja, subscrição pelo intermediário para revenda, como
também, extensivamente, um contrato destinado a tornar viável a colocação dos
títulos no mercado, pelo empenho de instituições intermediárias, mas sem
compromisso seu de subscrição.

Não sendo a subscrição por parte da instituição financeira uma cláusula inerente ao contrato de underwriting, mas ajustável ou não de acordo com a manifestação de vontade dos contratantes, torna-se em princípio inapropriado conceituar genericamente o underwriting como um contrato de pré-financiamento, com subscrição de títulos/valores mobiliários para revenda.

\footnotetext{
17 Serão necessários procedimentos internos da emissora em relação aos títulos/valores mobiliários não colocados, os quais dependerão da natureza dos mesmos.
} 


\section{CONCEITO DE UNDERWRITING}

A partir da confirmação da hipótese de que a subscrição pelo intermediário financeiro nem sempre acontece - o mesmo se diga em relação ao pré-financiamento -, a conceituação do contrato não pode deixar de levar em consideração que a subscrição e o préfinanciamento não se apresentam como características inerentes ao contrato, definidoras de sua natureza. Ao contrário, restarão caracterizadas, ou não, conforme a modalidade de garantia ajustada na prática. Nessa perspectiva, Romero-Pérez (2006, p. 95) afirma que o underwriting "consiste numa operação financeira que facilita o acesso das empresas ao mercado de capitais, com o objetivo de alcançar a expansão e o desenvolvimento tecnológico desejados frente aos desafios da globalização".

Com atenção às características e especificidades destacadas nos tópicos anteriores, é possível conceituar juridicamente o underwriting como o contrato cujo objeto é disciplinar as condições em que se operaram o processo de emissão, colocação e distribuição de títulos/valores mobiliários no mercado, celebrado entre sociedade empresária emissora e instituição ou consórcio de instituições financeiras autorizadas para esse fim, com o propósito de obtenção de recursos para o financiamento das atividades da sociedade emissora, com os intermediários atuando na coordenação da operação e assumindo (no caso de subscrição), ou não, o compromisso de pré-financiamento a colocação dos títulos/valores emitidos. Não menos importante, vale destacar que estrutura se adequa a concepção de um contrato consensual, bilateral, sinalagmático, oneroso, formal, e, em decorrência do risco que envolve seu objeto, é considerado negócio jurídico de natureza aleatória. Portanto, dependendo do arranjo contratual estabelecido entre a empresa emissora dos valores mobiliários e a instituição financeira envolvidas na transação, servirão como referencial normativo os art. 458 (que trata do contrato de esperança - emptio spei) e art. 459 (que regula a compra da coisa esperada - emptio res speratae), do Código Civil brasileiro. 


\section{UNDERWRITING NO ORDENAMENTO JURÍDICO BRASILEIRO}

No Brasil, sob o ponto de vista jurídico, o contrato de underwriting pode ser entendido como um instrumento contratual específico e complexo, que disciplina as relações entre a sociedade emissora e o intermediário (s) financeiro (s).

Não existe previsão específica sobre o underwriting no Código Civil ou em lei especial, embora o art. 82 da Lei 6.404/76, que trata da constituição de companhia por subscrição pública, indique que a subscrição somente pode ocorrer com intermediação de instituição financeira, mencionando ainda em seu $\S 1^{\circ}$ que o pedido de registro de emissão obedecerá às normas expedidas pela Comissão de Valores Mobiliários e, conforme alínea "c", será instruído com o prospecto, organizado e assinado pelos fundadores e também pela instituição intermediária. Por outro lado, no âmbito da regulação da Comissão de Valores Mobiliários (CVM), embora também não exista um detalhamento maior sobre a matéria ${ }^{18}$, há importantes disposições presentes em algumas instruções normativas, tais como as Instruções CVM 400/03, 480/09 e 476/09 ${ }^{19}$.

A Instrução CVM 400/03, que dispõe sobre as ofertas púbicas de valores mobiliários, nos mercados primário e secundário em geral, em seu Art. $3^{\circ}, \S 2^{\circ}$ impõe - com intuito de, em regra, impedir que se estabeleça uma relação direta entre o emissor e os destinatários da oferta - que as ofertas sejam realizadas com intermediação das denominadas "instituições intermediárias" ${ }^{20}$, isto é, instituições financeiras integrantes do sistema de distribuição de valores mobiliários ${ }^{21}$. Já o Art. 33 estabelece que o relacionamento do ofertante (emissor) com as instituições intermediárias deverá ser formalizado mediante contrato de distribuição de valores mobiliários. Dependendo das características da oferta pública de distribuição, a CVM poderá dispensar o requisito do Art. $3^{\circ}, \S 2^{\circ}$, com base na ressalva prevista nos termos do art. $4^{\mathrm{o}}$, “a seu critério e sempre observados o interesse público, a adequada informação e a proteção ao investidor", desde que, entre outras condições especiais, seja a oferta direcionada exclusivamente a investidores qualificados ${ }^{22}$. No mesmo sentido, o $\S 4^{\circ}$ e o $\S 5^{\circ}$ do Art. 33

\footnotetext{
${ }^{18}$ Ao contrário do que ocorre, por exemplo, no Código de Valores Mobiliários Português, que trata do tema de maneira mais aprofundada.

19 Procurou-se destacar os instrumentos normativos em vigor. A Instrução CVM 13/80, por exemplo, já estabelecia alguns deveres e responsabilidades à figura do underwriter, tendo sido revogada pela Instrução 480/09.

${ }^{20}$ Agrega-se, assim, um elemento subjetivo ao contrato.

${ }^{21}$ Nos termos do Art. 59, inciso III, da Instrução CVM 400/03, a distribuição sem intermediação de instituições intermediárias é considerada infração grave, exceto nos casos permitidos em Lei ou por dispensa da CVM.

22 São considerados investidores qualificados, na forma do Art. 109 da Instrução CVM 409/04: i) instituições financeiras; ii) companhias seguradoras e sociedades de capitalização; iii) entidades abertas e fechadas de
} 
dispõem que o próprio contrato de distribuição é dispensado nas ofertas públicas realizadas no âmbito de Programas de Distribuição Contínua em que a emissora e o distribuidor forem a mesma pessoa, hipótese em que a emissora é responsável por todas as obrigações das instituições intermediárias e do líder da distribuição, sem prejuízo de suas obrigações como emissora. A Instrução confere especial importância à questão da informação, consagrando o princípio do disclosure, corporificado principalmente no Art. 38, ao exigir a divulgação de um documento denominado prospecto, elaborado em conjunto pelo ofertante e o intermediário financeiro, devendo conter informações verdadeiras, atuais, claras e objetivas, e suficientemente precisas e completas em seu conteúdo e extensão, de modo a dar subsídios aos investidores na formação da decisão de investimento. Outro ponto de destaque se encontra no Art. 56, o qual atribui responsabilidade ao ofertante pela veracidade, consistência, qualidade e suficiência das informações prestadas em todo o processo; e também à instituição líder da oferta no sentido de tomar todas as cautelas necessárias e agir com elevados padrões de diligência, inclusive no que diz respeito as informações prestadas pelo ofertante, as quais deve certificar se são suficientemente precisas e completas em seu conteúdo e extensão.

O ANEXO VI da Instrução CVM 400/03 elenca uma série de cláusulas obrigatórias do contrato de distribuição, quais sejam: i) Qualificação da empresa emissora, da instituição líder e das demais Instituições Intermediárias envolvidas, se for o caso; ii) Assembleia Geral Extraordinária ou Reunião do Conselho de Administração que autorizou a emissão; iii) Regime de colocação dos valores mobiliários; iv) Total de valores mobiliários objeto do contrato, devendo ser mencionada a forma, valor nominal, se houver, preço de emissão e condições de integralização, vantagens e restrições, especificando, inclusive, aquelas decorrentes de eventuais decisões da Assembleia ou do Conselho de Administração que deliberou o aumento; v) Condições de revenda dos valores mobiliários pela instituição líder ou pelos demais Instituições Intermediárias envolvidas na distribuição, no caso de regime de colocação com garantia firme; vi) Remuneração da instituição líder e demais Instituições Intermediárias envolvidas na distribuição, discriminando as comissões devidas; vii) Descrição do procedimento adotado para distribuição; e viii) Menção a contratos de estabilização de preços e de garantia de liquidez, se houver.

Já o ANEXO VII trata da obrigatoriedade de apresentação de resumo mensal de colocação de valores mobiliários, cujo conteúdo deve discriminar as subscrições e

previdência complementar; iv) pessoas físicas ou jurídicas que possuam investimentos financeiros em valor superior a $\mathrm{R} \$ 300.000,00$ (trezentos mil reais) e que, adicionalmente, atestem por escrito a sua condição de investidor qualificado, mediante termo próprio; v) fundos de investimento destinados exclusivamente a investidores qualificados; vi) administradores de carteira e consultores de valores mobiliários autorizados pela CVM, em relação aos seus recursos próprios. 
integralizações realizadas em cada mês, ou, se for o caso, as vendas, assim como o saldo colocado no mês anterior, o total colocado e o saldo a colocar. Neste sentido, devem ser informados: i) Os valores mobiliários, por espécie e classe, se for o caso; ii) O detalhamento do tipo de investidor, ou seja: pessoas físicas, clubes de investimento, fundos de investimento, entidades de previdência privada, companhias seguradoras, investidores estrangeiros, instituições intermediárias participantes do consórcio de distribuição, instituições financeiras ligadas à emissora e/ou aos participantes do consórcio, demais instituições financeiras, demais pessoas jurídicas ligadas à emissora e/ou aos participantes do consórcio, demais pessoas jurídicas, sócios, administradores, empregados, prepostos e demais pessoas ligadas à emissora e/ou aos participantes (instituições intermediárias) na eventualidade de formação de consórcio, outros investidores (a especificar); e iii) O número de subscritores ou adquirentes e a quantidade de valores mobiliários subscritos e integralizados ou adquiridos.

Outra Instrução importante é a CVM 480/09, que versa sobre o registro de emissores de valores mobiliários admitidos à negociação em mercados regulamentados de valores mobiliários, quais sejam, bolsa, balcão organizado e balcão não organizado. O Art. $2^{\circ}$ opera uma distinção entre emissor de categoria "A" e emissor de categoria "B". Ao obter registro na categoria "A" o emissor fica autorizado a negociar quaisquer valores mobiliários de sua emissão em mercados regulamentados de valores mobiliários - portanto, todos aqueles títulos/valores listados no art $2^{\circ}$ da lei 6.385/76. Registrado na categoria "B", o emissor fica também autorizado a negociação de valores mobiliários de suas emissão em mercados regulamentados de valores mobiliários, mas com restrição dos seguintes: i) ações e certificados de depósito de ações; ou ii) valores mobiliários que confiram ao titular o direito de adquirir ações e certificados de depósito de ações, em consequência da sua conversão ou do exercício dos direitos que lhes são inerentes, desde que emitidos pelo próprio emissor ou por uma sociedade pertencente ao grupo do referido emissor ${ }^{23}$.

Recentemente, a Instrução CVM 476/09, que dispõe sobre as ofertas públicas de valores mobiliários distribuídas com esforços restritos - aquelas destinadas exclusivamente para investidores qualificados e intermediadas por instituições integrantes do sistema de distribuição de valores mobiliários -, sofreu importantes alterações por intermédio da Instrução CVM 551, de 25 de setembro de 2014, a qual operou modificações relevantes na sistemática da prática de colocação e distribuição de valores mobiliários. Foram introduzidos novos elementos ao Art. $3^{\circ}$, que tornam as ofertas públicas com esforços restritos mais

\footnotetext{
${ }^{23}$ É possível ao emissor requerer à CVM, por intermédio da Superintendência de Relações com Empresas (SEP), a conversão de uma categoria de registro em outra.
} 
atrativas para os emissores e intermediários, passando a ser permitida a procura de, no máximo, 75 (setenta e cinco) investidores qualificados - em vez de 50 (cinquenta); e que os valores mobiliários ofertados possam ser subscritos ou adquiridos por, no máximo, 50 (cinquenta) investidores qualificados - em vez de, no máximo, 20 (vinte).

\section{Algumas características do CONTRATo de UNDERWRiting No ORdenamento JURÍDICO BRASILEIRO}

Tendo em conta a previsão específica por parte de Instruções Normativas da CVM, inclusive com disposição expressa acerca de determinadas cláusulas contratuais obrigatórias, tem-se o contrato de distribuição como um tipo legal nominado, o qual configura um tipo contratual único ${ }^{24}$. Não obstante, em virtude de diversas disposições normativas aplicáveis, percebe-se que o "contrato de distribuição" envolve a disciplina jurídica e referências a inúmeras etapas de um processo complexo, que vão desde atos preliminares à emissão, passando pela emissão em si, subscrição (ou não) pelo intermediário, coordenação, colocação e distribuição pública de valores mobiliários, entre outros. Determinados elementos podem ser distintos e, na prática, serão inseridos pelas partes intervenientes na formação do tipo contratual em questão, como por exemplo as modalidades de garantia assumidas pela instituição financeira intermediária.

Nesta relação contratual complexa a atividade de prestação de serviços por parte da instituição financeira estará sempre presente - com a realização não somente da função de intermediação, como também do assessoramento ao emissor em diversas etapas do processo, como por exemplo na elaboração do prospecto -, ao passo que a atividade especulativa (subscrição para revenda) poderá estar presente ou não, dependendo da modalidade de garantia assumida pelo intermediário. Conforme visto, a subscrição pela instituição financeira e o pré-financiamento não são cláusulas inerentes ao contrato, mas ajustáveis ou não de acordo com a manifestação de vontade dos contratantes.

Outra característica importante é que, não obstante seja prevista e disciplinada a prestação de determinados serviços pelas instituições financeiras intermediárias às sociedades

\footnotetext{
${ }^{24}$ O Código de Valores Mobiliários de Portugal traz previsões específicas, entre outros, para os seguintes contratos: "contrato de assistência" (Art. 337), "contrato de colocação" (Art. 338), "contrato de tomada firme" (Art. 339) e "contrato de consórcio para assistência ou colocação" (Art. 341-1). Em que pesem tais estipulações, há controvérsias na doutrina portuguesa sobre se se está diante de um único tipo contratual, ou se se tratam de tipos distintos. Para Catarina Rodrigues (2012, p. 58), está-se diante de um único tipo contratual nominado, a colocação de valores mobiliários, sendo a tomada firme uma de suas modalidades. Em sentido contrário, Rui Pinto Duarte (2000, p. 354-357) destaca a existência de diferentes tipos contratuais.
} 
emissoras, a relação entre as partes e o contrato têm características próprias, de colaboração efetiva em prol de um empreendimento comum, que se lhe atribuem um caráter mercantil (empresarial), devendo restar afastadas do âmbito de aplicação do Código de Defesa do Consumidor $^{25}$. Do mesmo modo, embora tenha uma instituição financeira na condição de parte interveniente o contrato de colocação não deve ser entendido como um contrato bancário, na medida em que apresenta características muito próprias que o diferenciam dos demais contratos aos quais se atribui esta natureza.

No mais, como diversas condições e cláusulas do contrato não são preestabelecidas ou impostas unilateralmente por um dos intervenientes, mas sim previamente discutidas pelas partes, parece não restar caracterizado como contrato de adesão ${ }^{26}$. Ao contrário, pode ser identificado como um contrato-tipo que, segundo definem Marcelo Bertoldi e Marcia Carla Ribeiro (2013, p. 757), é aquele que, muito embora contenha cláusulas pré-definidas, põe os contratantes em posição de igualdade e oportunidade de discutir e ajustar as suas condições particulares.

\section{CONCluSÃo}

Ao longo da pesquisa, percebeu-se que os agentes econômicos dispõem de diferentes opções com vistas à obtenção e manutenção de níveis adequados de recursos para o exercício de suas atividades e projetos de desenvolvimento. Dentre tais alternativas, encontra-se o processo de emissão, colocação e distribuição de títulos/valores mobiliários, operação(ões) instrumentalizada(s) juridicamente por intermédio do underwriting.

Trata-se de um instrumento contratual específico e complexo que disciplina as relações entre a sociedade emissora e o intermediário(s) financeiro numa oferta pública, que guarda características de contrato empresarial, mas a liberdade das partes contratantes se encontra limitada em função da necessidade de observação e respeito às exigências constantes dos instrumentos normativos expedidos pela Comissão de Valores Mobiliários.

\footnotetext{
25 Diferentemente das relações de natureza mercantil, os contratos abrangidos pelo Código de Defesa do Consumidor decorrem das transações firmadas entre partes desiguais, tomando como referência a vulnerabilidade técnica, jurídica e econômica. Portanto, a contratação manejada entre instituições financeiras e sociedades empresárias, visando a captação de recursos através da emissão de valores mobiliários e, em contrapartida, a garantia dos riscos, enquadra-se na seara empresarial, sem cunho consumerista.

${ }^{26} \mathrm{O}$ contrato de adesão "é aquele em que uma das partes, o aderente, não tem condições de influenciar $\mathrm{n}$ redação de suas cláusulas, cabendo a ele tão somente duas alternativas: aceitar ou não o contrato da forma como lhe é apresentado" (BERTOLDI; RIBEIRO, 2013, p. 757).
} 
No Brasil, diferentemente do que ocorre no Código de Valores Mobiliários de Portugal, o underwriting tem sido tratado como um tipo contratual único, definido no âmbito da Instrução CVM 400/03 como “contrato de distribuição de valores mobiliários". Não obstante, pelo exame dos conteúdos das disposições presentes em algumas instruções normativas, percebe-se que envolve a disciplina jurídica e referências a inúmeras etapas de um processo complexo, que vão desde atos preliminares à emissão, passando pela própria emissão em si, subscrição (ou não) pelo intermediário, coordenação, colocação e distribuição pública de valores mobiliários junto aos investidores, entre outros atos. Na prática, alguns elementos podem ser distintos e serão inseridos pelas partes intervenientes na formação do tipo contratual em questão, de acordo com as suas necessidades específicas, como por exemplo as diferentes modalidades de garantia assumidas pela instituição financeira intermediária.

As modalidades de garantia eventualmente assumidas pela instituição financeira intermediária são de extrema relevância para a solução do problema de pesquisa apresentado na introdução, uma vez que somente em alguns contratos de underwriting haverá efetiva garantia de subscrição por parte do underwriter. Como tal vinculação relacionada à garantia pode englobar a totalidade dos títulos (caso do underwritng firme), uma parcela não subscrita pelo público (caso do stand by) -, ou mesmo não existir (caso do best efforts), não é apropriado definir genericamente o underwriting como um contrato de pré-financiamento, pelo qual a instituição financeira será sempre responsável pelo direcionamento de recursos ao emissor dos títulos/valores mobiliários, subscrevendo-os para em seguida revendê-los ao mercado. A subscrição pelo intermediário poderá ocorrer, ou não. O mesmo em relação ao pré-financiamento.

Adicionalmente, do exame das instruções normativas da Comissão de Valores Mobiliários que disciplinam a matéria percebem-se importantes questões jurídicas em torno do underwriting, como a obrigatoriedade de intermediação por parte de instituições financeiras integrantes do sistema de distribuição de valores mobiliários - seu caso específico de dispensa -, o rol de cláusulas obrigatórias do contrato de distribuição - dispensado nas ofertas públicas realizadas no âmbito de Programas de Distribuição Contínua em que a emissora e o distribuidor forem a mesma pessoa -, obrigatoriedade de apresentação de resumo mensal de colocação de valores mobiliários, distinção entre emissor de categoria " $A$ " e emissor de categoria "B", assim como o advento de recentes e importantes modificações na sistemática da prática de colocação e distribuição de valores mobiliários, que tornam as 
ofertas públicas com esforços restritos mais atrativas para os emissores e intermediários, entre outros.

\section{REFERÊNCIAS BIBLIOGRÁFICA}

BERTOLDI, Marcelo M.; RIBEIRO, Marcia Carla Pereira. Curso Avançado de Direito Comercial. 7 ed. rev. atual. e ampl. São Paulo: Revista dos Tribunais, 2013.

BOCATER, Maria Isabel do Prado. Contrato de Underwriting. Irregularidades. Revista de Direito Bancário e do Mercado de Capitais, São Paulo, v. 3, p. 255-261, set. 1998.

CASAGRANDE NETO, Humberto; SOUSA, Lucy A.; ROSSI, Maria Cecília. Abertura do capital de empresas no Brasil: um enfoque prático. 3. ed. rev. e atual. São Paulo: Atlas, 2000.

COMISSÃO DE VALORES MOBILIÁRIOS - CVM. BRASIL. Instruções Normativas. Disponível em: <http://www.cvm.gov.br>. Acesso em: 15 jan. 2017.

COMISSÃO DO MERCADO DE VALORES MOBILIÁRIOS - CMVM. PORTUGAL. Código de Valores Mobiliários. Disponível em: 〈http://www.cmvm.pt〉. Acesso em: 16 jan. 2017.

CORDEIRO FILHO, Ari. Manual de Abertura das Companhias. Rio de Janeiro: IBMEC/APEC, 1981.

DUARTE, Rui Pinto. Contratos de Intermediação no Código dos Valores Mobiliários. Cadernos do Mercado de Valores Mobiliários, n. 7, p. 352-373, abr. 2000.

EIZIRIK, Nelson. Aspectos jurídicos do "underwritng". Revista de Direito Mercantil, Industrial, Econômico e Financeiro, São Paulo, Nova Série, n. 66, ano XXVI, p. 19-28, abr.jun. 1987.

; GAAL, Ariádna B.; PARENTE, Flávia; HENRIQUES, Marcus de Freitas. Mercado de Capitais: regime jurídico. 3. ed. rev. e ampl. Rio de Janeiro: Renovar, 2011.

MELLO, Carlos Barbosa; JUNQUEIRA, Rodrigo Azevedo; BERCITTO, Bruno Rodrigues. A Responsabilidade Civil das Instituições Financeiras em Ofertas Públicas de Valores Mobiliários. In: CANTIDIANO, Luiz Leonardo; MUNIZ, Igor (orgs.). Temas de direito bancário e do mercado de capitais. Rio de Janeiro: Renovar, 2014.

RODRIGUES, Catarina Figueiredo. Contrato de Colocação com Tomada Firme (Breves Notas). Cadernos do Mercado de Valores Mobiliários, n. 41, p. 35-64, abr. 2012.

ROMERO-PÉREZ, Jorge Enrique. Underwriting: contrato financiero moderno. Revista de Ciencias Jurídicas, n. 109, p. 91-118, enero-abril 2006.

TORRES, Gustavo Ruiz. El contrato de underwriting. Cuadernos de Investigaciòn y Jurisprudencia, ano 3, n. 8, p. 115-125, 2010. 
VÁSQUEZ, José Arquímedes Fernández. El contrato de underwriting. Revista Jurídica SSSIAS, ano 5, n. 5, p. 1-28, nov. 2012.

WALD, Arnoldo; EIZIRIK, Nelson. Responsabilidade do Underwriter pela Veracidade das Informações em um Emissão Pública. Revista da CVM, Rio de Janeiro, v. 2, n. 5, p. 53-62, 1984. 